\title{
Crónica
}

\section{¿Es ético utilizar la criopreservación como técnica para hacer más eficiente la fertilización in vitro?}

\author{
Publicado por diario La Tercera el 20 de octubre de 2013, página 44, sección FRENTE A \\ FRENTE (http://www.latercera.com/)
}

\section{EL DERECHO A FORMAR FAMILIA}

Disponible en: http://www.latercera.com/noticia/ opinion/ideas-y-debates/2013/10/895-547821-9-elderecho-a-formar-familia.shtml

Esta técnica permite detener procesos biológicos de embriones microscópicos (2 a 100 células) por tiempos indefinidos, manteniendo la capacidad de reactivar el ciclo vital al ser descongelado. Con la tecnología actual de vitrificación, puedo certificar que 90 a $97 \%$ de los embriones de $5^{\circ}$ día (blastocisto) sobrevive al ser descongelado. En nuestra experiencia en 2012 , la tasa de embarazo y aborto obtenida en 392 ciclos de fertilización in vitro (FIV) con embriones frescos, y 102 con embriones congelados, fueron casi exactas $(48,6 \%$ y $48 \%$ y $16,2 \%$ y $16,3 \%$, respectivamente). Así, la vitrificación de blastocisto no afecta sus posibilidades de anidarse y se disminuye la multigestación al transferir uno o dos embriones secuencialmente. Los bebés nacidos no ven afectado su peso al nacer ni su salud general. La frecuencia de malformaciones estudiadas en 1.500 bebés nacidos en Latinoamérica es $1,4 \%$, aún más baja que lo encontrado en 16.500 bebés nacidos en el mismo período de embriones frescos $(1,9 \%)$.

La vitrificación embrionaria no afecta la posibilidad de nacer de un embrión sano, no expone a los bebés y sus madres a riesgos de salud y disminuye la chance de embarazo múltiple.

¿Qué opinan los chilenos sobre la criopreservación embrionaria?

Esta tecnología genera dilemas éticos y sociales complejos, difíciles de sobrellevar. Nadie está indiferente frente a la decisión de congelar y las parejas viven estos procesos con preocupación y responsabilidad. El conflicto mayor resulta de qué hacer con los embriones preservados si a futuro no quieren o no pueden tener más hijos. Esto es especialmente complejo en instituciones como Clínica Las Condes, donde los consentimientos establecen que los embriones no pueden ser desechados y deben ser usados por ellos o donados a terceros. Entre 2011 y 2012, de 789 tratamientos de FIV, sólo 36 pacientes $(4,6 \%)$ expresaron la decisión de no congelar embriones. La alta aceptación a la congelación es consonante con resultados de la encuesta de opinión realizada y publicada por la UDP, que demostró que, independiente de la edad, género y grupo socioeconómico, más del $75 \%$ de los 1.500 encuestados están a favor de la criopreservación embrionaria para facilitar que una pareja tenga hijos.

¿Es ético realizar procedimientos de fecundación asistida sin criopreservación embrionaria?

Sí, en la medida que la pareja infértil entienda y acepte las limitantes y las bajas posibilidades de éxito. Lo que no es ético es negarles a mujeres y hombres el derecho a congelar embriones que les permita concebir de manera más eficiente, segura y menos costosa. Todo tratamiento médico debe propender a resolver las enfermedades con la mayor eficiencia, el menor riesgo y el menor costo para la persona enferma. En FIV, esto no se logra sin criopreservación embrionaria.

Independiente de si el embrión es considerado sujeto u objeto de derecho, desde una perspectiva biológica no se daña al embrión; desde la moral, no existen razones para impedir que personas adultas e informadas recurran a la ciencia para formar una familia de manera segura y eficiente. Negarles ese derecho es contrario a la ética y constituye un atentado contra el derecho humano a no ser discriminado por una discapacidad reproductiva. Es también contrario a la ética sobreponer supuestos derechos de embriones por sobre el derecho de las personas 
a formar una familia y vivir la vida privada y familiar sin injerencias arbitrarias.

Dr. Fernando Zegers $\mathrm{H}$. Director Programa de Ética y Políticas Públicas en Reproducción Humana UDP. Miembro Unidad de Medicina Reproductiva, Clínica las Condes.

\section{PROCEDIMIENTO INACEPTABLE}

Disponible en: http://www.latercera.com/noticia/ opinion/ideas-y-debates/2013/10/895-547822-9procedimiento-inaceptable.shtml

Un debate lúcido y razonable sobre este tema requiere dos precisiones previas. La primera se refiere a la pregunta de en qué momento se inició nuestra vida.

La investigación biológica ha despejado toda duda sobre este tema. Esta se inicia con la fecundación. Ya en 1876, Ernst Haeckel, un evolucionista materialista, describía el proceso de la concepción diciendo: "Si bien debemos considerar al espermatozoide como una célula tan real como el óvulo, y el proceso de la concepción como la fusión de ambos, debemos considerar a la célula resultante como un organismo nuevo e independiente. La mezcla de ambas células es el germen del niño o el nuevo organismo concebido". Las investigaciones más recientes han enriquecido, con nuevos descubrimientos, este hecho asombroso y fascinante. A este respecto, en 2002 la revista Nature, una de las de mayor prestigio científico, publicó el artículo denominado "Su destino desde el primer día".

La segunda precisión se refiere al derecho a la vida. La Declaración Universal de los Derechos Humanos lo reconoce como igual e inalienable para todos y cada uno de los miembros de la familia humana. Hoy han surgido otras visiones que consideran que se puede aceptar una cierta gradualidad de este derecho en las primeras etapas del desarrollo, dependiendo de cuándo se van cumpliendo ciertas etapas, como serían el inicio del desarrollo del sistema nervioso, la capacidad de sentir dolor o placer y de tener autoconciencia. No hay espacio para señalar la debilidad de estas visiones, y la trascendencia y consecuencias que tienen para la vida de la sociedad y la justicia.

Sin duda, para quienes el derecho a la vida es igual e inalienable para todos (DD.HH.), la criopreservación no tiene lugar, por los riesgos que implica para la vida y por el destino final de los embriones congelados no implantados, como lo demuestran numerosos estudios y la realidad de miles de embriones congelados que han sido abandonados. Se estima que sólo entre un 60 y $75 \%$ de los embriones sobrevive al proceso de congelación-descongelación, y en los que sobreviven, se estudian posibles alteraciones en su desarrollo. Es un hecho comprobado que su destino definitivo es incierto. En efecto, corren el riesgo de ser destruidos o abandonados y a estar congelados indefinidamente en los casos que los padres -por diversas razones- ya no puedan o no quieran recibirlos. Este es un grave problema mundial, pues son miles los embriones congelados que sufren la incertidumbre que conllevan estas situaciones. La criopreservación es una técnica que se asocia a la fertilización in vitro con el objetivo de maximizar la eficiencia de un ciclo de hiperestimulación ovárica, con lo que se obtienen varios óvulos que son fecundados. Como no es conveniente implantar más de dos a la vez, el resto se congela para evitar los riesgos, costos y molestias que tendría para la mujer un nuevo ciclo de hiperestimulación si la técnica fracasó en el primer intento, pues tendría embriones congelados de reserva. Pero el ser humano nunca debe ser instrumentalizado en aras de una mayor eficiencia. Todo hijo requiere respeto y cariño por parte de los padres y de la sociedad, para cautelar su vida, su integridad y su futuro. "Cada nueva generación ofrece una oportunidad a toda la humanidad" (Convención de Derechos del Niño).

Dr. Patricio Ventura-Juncá Director Instituto de Bioética Universidad Finis Terrae. Profesor Titular Universidad Católica. 